Document downloaded from:

http://hdl.handle.net/10251/47378

This paper must be cited as:

Rayón Encinas, E.; Bonache Bezares, V.; Salvador Moya, MD.; Bannier, E.; Sánchez, E.; Denoirjean, A.; Ageorges, H. (2012). Nanoindentation study of the mechanical and damage behaviour of suspension plasma sprayed $\mathrm{TiO} 2$ coatings. Surface and Coatings Technology. 206(10):2655-2660. doi:10.1016/j.surfcoat.2011.11.010.

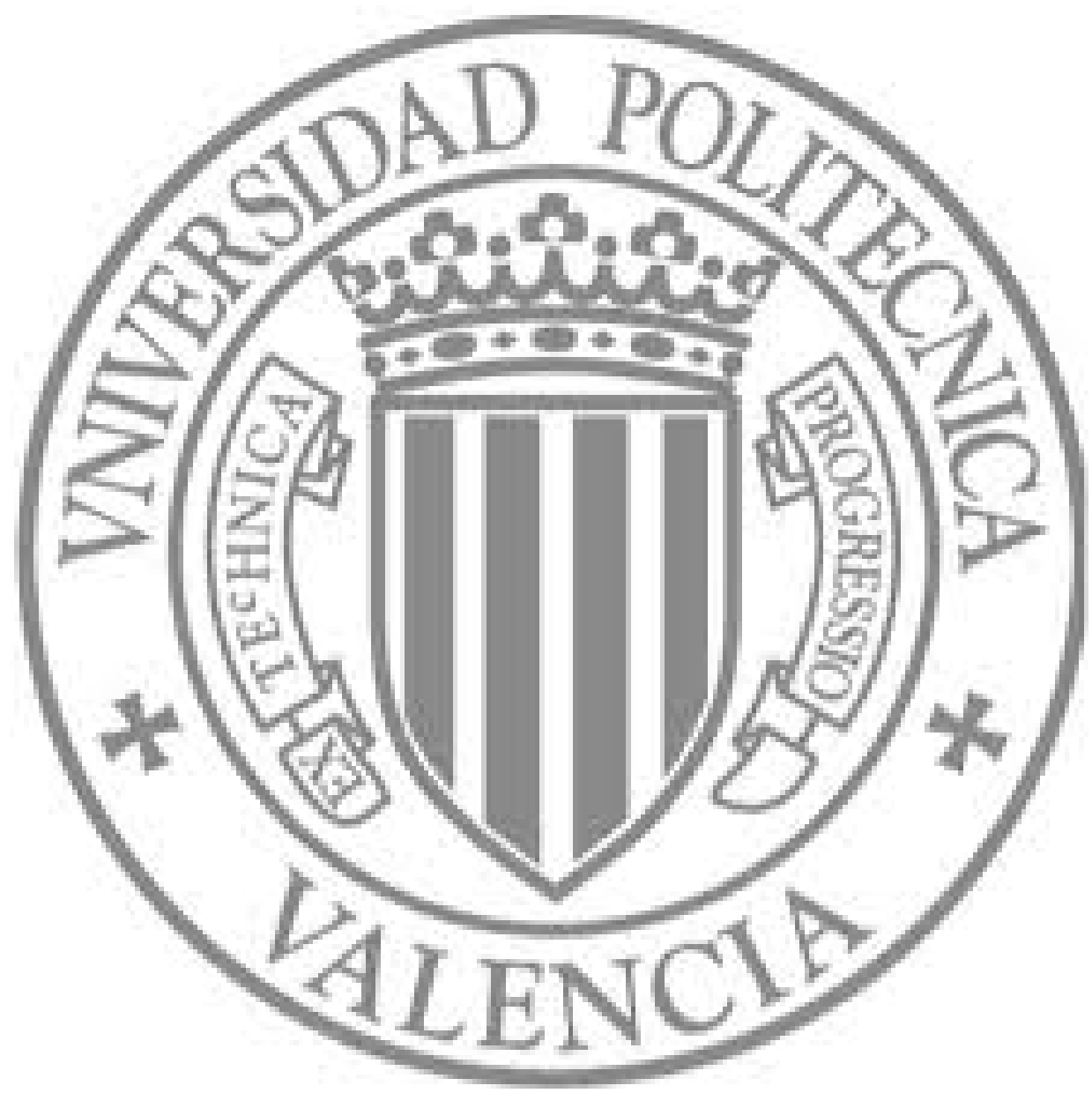

The final publication is available at

Copyright Elsevier 


\title{
Nanoindentation study of the mechanical and damage behaviour of suspension plasma sprayed $\mathrm{TiO}_{2}$ coatings
}

E. Rayón ${ }^{1}{ }^{1}$, V. Bonache ${ }^{1}$, M.D. Salvador ${ }^{1}$, E. Bannier ${ }^{2}$, E. Sánchez ${ }^{2}$, A. Denoirjean ${ }^{3}$, H. Ageorges ${ }^{3}$

${ }^{1)}$ Instituto de Tecnología de Materiales, Universitat Politècnica de Valencia, Camí de Vera s/n. E-46022, Valencia, Spain.

2) Instituto de Tecnología Cerámica, Campus Universitario Riu Sec. Vicent Sos Baynat, s/n. E12006, Castellón, Spain.

${ }^{3)}$ SPCTS, UMR CNRS 6638, Université de Limoges, Faculté des Sciences et Techniques, 123 avenue Albert Thomas, 87060 Limoges, France

\author{
*Corresponding author: \\ Dr. Emilio Rayón Encinas \\ Instituto de Tecnología de Materiales \\ Universidad Politécnica de Valencia \\ Camí de Vera s/n, E46022. Valencia, Spain \\ e-mail: emraen@upvnet.upv.es \\ Fax: +34 963877629 \\ Phone: +34667238511
}

\section{Abstract}

$\mathrm{TiO}_{2}$ coatings can be used as self-cleaning surfaces owing to their photocatalytic and hydrophilic properties. Suspension plasma spray (SPS) has proven to be a feasible and cheap technique for producing self-cleaning surfaces with acceptable photo-activity. This paper presents a nanoindentation study of the mechanical properties (hardness, Young's modulus and scratch resistance) of photoactive layers of suspension plasma sprayed $\mathrm{TiO}_{2}$ coatings applied on to glass substrates. Microstructure observation showed that the rutile grains were surrounded by fine anatase crystals. Under the same spraying conditions, the resulting anatase/rutile concentrations varied depending on the cooling rate (the substrate being either cooled with water or in air). The results showed that higher concentrations of anatase, which is softer than rutile, reduced the scratch damage and increased the friction coefficient. 
Keywords: Suspension Plasma Spray, Nanoindentation, $\mathrm{TiO}_{2}$, Microstructure characterisation, Photocatalysis.

\section{Introduction}

$\mathrm{TiO}_{2}$ semiconductors are used in solar cells, optical devices, and in photocatalytic reactors which references can find elsewhere [1-5]. The photocatalytic property is generated when $\mathrm{TiO}_{2}$ is exposed to UV light, owing to its band gap centred between $3.0 \mathrm{eV}$ and $3.2 \mathrm{eV}$, though this energy can be tuned to be sensitive to visible light by means of specific dopants $[6,7]$. The liberated electrons previously excited by light radiation can reach the $\mathrm{TiO}_{2}$ surface and then react with the organic matter deposited on the photoactive layers, degrading the organic molecules [8]. This degradation produces free active radicals, which can react or dissolve in water (in a solution configuration). In addition, activated $\mathrm{TiO}_{2}$ is very hydrophilic and the contact angle of water is very low, creating a slippery surface. These properties make such materials highly appropriate to be employed as self-cleaning [9-11] surfaces. Other recent applications include wastewater treatment and disinfection $[12,13]$.

$\mathrm{TiO}_{2}$ coatings can be produced by various techniques, such as atmospheric plasma spray, APS. APS is a particularly appropriate technique because a large area of $\mathrm{TiO}_{2}$ can be easily deposited without any special requirements, such as vacuum pressures or reactive atmospheres [14-17]. In the APS technique, the material is fed in powder form into a high-energy flame and the melted particles are deposited on to the substrate, forming the coating. When very fine or nanometre-sized particles are sprayed, the material needs to be in the form of aggregates because the low acceleration of such very small masses is insufficient to allow them to reach the substrate. In the suspension plasma spray, SPS, used in this study, nanoparticle kinetic flight was improved by using a liquid carrier suspension containing the dispersed nanoparticles [18]. According to the literature [19-21], the SPS coatings obtained using nanopowder feedstock exhibit improved characteristics, because these coatings contain less porosity than APS and have a denser nanostructure. In recent studies on nanostructured $\mathrm{TiO}_{2}$ coatings produced by SPS [17], photocatalytic activity was reported on observation of methylene blue degradation under UV radiation [23, 24]. 
$\mathrm{TiO}_{2}$ can be found in amorphous, anatase, and rutile phases. Independently of the technique used to generate the $\mathrm{TiO}_{2}$ coatings, high concentrations of anatase are required to obtain high ratios of photocatalytic activity $[25,26]$. However, the compositional balance between these phases affects the mechanical properties of the coatings, making it necessary to find a compromise between optimal photocatalytic activity and good mechanical response. Lech Pawlowski et al. [27] conducted a nanoscratch study on sprayed $\mathrm{TiO}_{2}$ coatings and examined the critical load required to generate coating failure on a substrate. Studies are unavailable in the literature, however, on the nanomechanical and tribological behaviour of such coating components.

The present study was undertaken to characterise the nanomechanical properties and damage resistance of suspension plasma sprayed $\mathrm{TiO}_{2}$ coatings. The studied coatings were chosen from a series of suspension plasma sprayed $\mathrm{TiO}_{2}$ coatings obtained in a previous work [28]. The following two coatings, which were sprayed under the same conditions, were chosen: the first was applied on to a substrate cooled in air, which gave rise to a homogenous anatase-rutile phase distribution; the second was applied on to a substrate cooled with water, which yielded a segregated anatase-rutile phase distribution. Nanoindentation tests were then performed on these coatings: the results from the scratch tests were correlated with the hardness $(H)$ and Young's modulus $(E)$ of the phase distribution. The constituent microstructures and phases were observed using a field-emission scanning electron microscope (FE-SEM).

\section{Experimental Conditions}

\subsection{Materials and coatings preparation}

$\mathrm{TiO}_{2}$ supplied by Evonik Industries under reference Aerodisp W 740 X was used in an aqueous suspension at $40 \mathrm{wt} \%$. Aggregates smaller than $100 \mathrm{~nm}$ made up of $20-30 \mathrm{~nm}$ nanoparticles of $90 \mathrm{wt} \%$ anatase $+10 \mathrm{wt} \%$ rutile provided the suspension with a viscosity below $1000 \mathrm{mPaS}$ and a density of $1.41 \mathrm{~g} / \mathrm{cm}^{3}$. 
The coatings were deposited using a F4-MB monocathode torch (Sulzer Metco, Wolhen Switzerland) with a $6 \mathrm{~mm}$ internal diameter anode. The substrates were preheated at $300{ }^{\circ} \mathrm{C}$ to enhance coating adhesion.

Suspension injection was performed through a calibrated diaphragm of $150 \mu \mathrm{m}$ diameter. The plasma gas was a mixture of $\mathrm{He}$ and $\mathrm{Ar}$ with flow rates of $10 \mathrm{l} / \mathrm{min}$ and $50 \mathrm{l} / \mathrm{min}$, respectively. Arc intensity was kept constant at $400 \mathrm{~A}$. The surfaces of the deposited material were cooled either by spraying water $\left(8 \mathrm{mls}^{-1}\right)$ or by spontaneous cooling along the projection procedure.

Pyrex glass specimens in the form of $25 \mathrm{~mm}$ diameter disks were used as substrates. The substrates were cleaned with ethanol and dried in air prior to coating deposition. After deposition, cross-sections of the resulting specimens were polished down to 0.25 $\mu \mathrm{m}$ abrasives. Surface roughness, measured by a standard surface roughness tester, was $R a=1.1 \pm 0.2 \mu \mathrm{m}$ for the coatings obtained under both types of cooling conditions. Further details on the photoactivity behaviour and composition characterization by Raman microprobe analysis on the cross-sections are given in a previous paper [28].

\subsection{Sample characterisation procedure}

An Agilent G-200 nanoindenter was used to analyse the $H$ and $E$ of the resultant polished coating cross-sections with a calibrated Berkovich indenter. The indentations were performed at constant depth mode. The stiffness used for the $H$ and $E$ calculation was obtained by continuous stiffness measurement $[29,31]$ CSM, in the $45-50 \mathrm{~nm}$ average depth range. The scratch tests were conducted with the same apparatus, using a lateral force sensing module and a spherical sapphire indenter with a $100 \mu \mathrm{m}$ diameter. The scratches were made on the sample surface applying a dynamic load from $0 \mathrm{mN}$ to $100 \mathrm{mN}$ along a $100 \mu \mathrm{m}$ distance. Cross-section microstructure and wear tracks were observed using a HITACHI S-4100 field-emission scanning electron microscope (FE-SEM). 


\section{Results and discussion}

Figure 1 shows the cross-section FE-SEM images of the two types of coatings. These images show that the thicknesses reached were between the $30 \mu \mathrm{m}$ to $40 \mu \mathrm{m}$. Figs. $1 \mathrm{a}$ and $1 b$, the latter being at higher magnification, show that the coatings cooled in air exhibited a microstructure made up of $(I)$ harder and larger grains surrounded by (II) softer and smaller grains. These morphologies were well characterised by Raman microprobe analysis in a previous work [28] and correspond to rutile and anatase $\mathrm{TiO}_{2}$ phases, respectively. Fig. $1 \mathrm{~b}$ shows that the coating consisted of dense material without measurable porosity. Hereafter, this specimen is designated $A+R$ (Anatase + Rutile on surface). In contrast, the water-cooled samples (Fig. 1c) displayed a phase distribution in the form of a bi-layer structure. A great rutile grain concentration was found at the substrate surface, while the anatase microstructure lay at the coating outer surface. Hereafter, this specimen is designated $A$ (only Anatase on surface).

This bi-layer structure may be explained as follows: the high temperature reached in the flame (3000-8000 K) melted all sprayed material. Subsequent fast cooling caused a significant amount of particles to crystallise as anatase phase, despite the rutile transformation occurs at $700-800{ }^{\circ} \mathrm{C}$. In previous studies $[32,33]$ this transformation was reported when the $\mathrm{TiO}_{2}$ suspension was sprayed directly into water, producing a high $\mathrm{TiO}_{2}$ content in the form of anatase. However, the material sprayed close to the substrate was transformed into rutile owing to the higher temperature of the substrate and the subsequently deposited hot material. A previous study [28] confirmed this double-layer structure of anatase-rutile, independently of whether steel or glass was used as substrate material.

The $H$ and $E$ features of the observed microstructures were analysed by means of a square grid of 300 nanoindentation tests on the sample cross-section with homogeneously distributed anatase and rutile $(A+R$ specimen). The distance between each imprint was programmed to be $1 \mu \mathrm{m}$. This sample was chosen because of the more homogeneous anatase and rutile distribution throughout the coating. The distribution of the mechanical properties was then represented by histogram distributions and surface mappings in which each $H$ and $E$ result was plotted on the 
axis coordinates with the same dimensions and locations as in the tested area. The distribution of the $H$ and $E$ results at $40-50 \mathrm{~nm}$ depth, is shown in Figure 2. As this type of plot depends to a great extent on the choice of bin size, the distributions were also plotted by the normal probability distributions acquired previously by fitting the cumulative results. This procedure has been described previously in similar studies [34, 35]. The $H$ distribution clearly showed two main values centred at $8.5 \mathrm{GPa}$ and 16.5 $\mathrm{GPa}$. These results are close to those reported for $\mathrm{TiO}_{2}$ anatase and rutile respectively [36]. The $E$ histogram was difficult to deconvulate owing to the similar $E$ values expected for both phases and their greater elastic stress field beneath the indenter [37]. The $H$ and $E$ maps acquired on the $A+R$ sample are shown in Figure 3 . The foregoing results confirm that the microstructure of the larger grains, which consisted of rutile, displayed the harder behaviour. These grains were surrounded by the anatase matrix that, though retaining its initial nanostructure, was the softer phase.

In order to compare the tribological properties of the $A$ and $A+R$ specimen surfaces, scratch tests were performed on those surfaces. FE-SEM images of the tracks produced under the test conditions used are shown in Figure 4. The maximum load attained corresponded to the bottom of the wear track, the experiment starting at zero load at the top. The friction force $\left(F_{\mu}\right)$ and coefficient of friction $(\mu)$ recorded during the scratch tests are plotted in Figure 5. The linear behaviour of $F_{\mu}$ under the test conditions used assured that no critical load was reached. The increase in friction when scratch load rose agreed with Nosonovsky and Bhushan's observation [38, 39] that is, at small contact sizes, $\mu$ increased when contact size and the applied load rose.

The recorded $\mu$ at the experimented conditions was higher on the $A$ specimen surface, resulting an average value of $\mu=0.7$, compared with $\mu=0.3$ on the $A+R$ surface. This behaviour may be explained by the theory of multi-asperity contacts put forward by Zhang et al. [40, 41]. According to this theory, when two surfaces are in contact, a part of the load is distributed on the contact area of the asperities and/or on the contact area of debris particles. Thus, the resultant $\mu$ consists of the sum of three components:

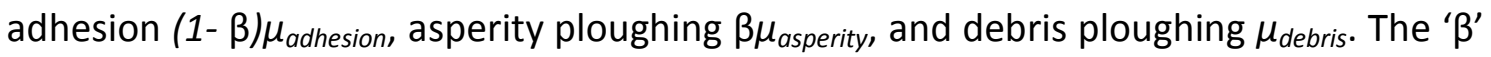
coefficient is a value that depends on surface roughness. The spherical indenter used in this study assured that multiple-asperity contact conditions were in place, in which 
there was a mechanical interlocking between the contacting surfaces, despite the low applied loads.

The main friction component on the $A$ specimen was $(1-\beta) \mu_{a d h e s i o n}$. This was justified by observing the slide pattern, in which no evidence of asperity or debris ploughing was found. The wear track is shown at higher magnifications in the FE-SEM images of Figure 6. On the specimen $A$ wear track (Fig. 6a), several transverse lines crossing the slide pattern as a plastic/adhesive wear mechanism may be observed, which explains the higher recorded friction.

On the other hand, Fig. $6 \mathrm{~b}$ shows that a number of particles were pulled out of the $A+$ $\mathrm{R}$ specimen. This was probably the result of small clusters of rutile particles detaching from the anatase matrix when the cohesion of the plastically deformed matrix failed. It may, further, be observed that the asperities were levelled inside the wear track: the inter-asperity voids were presumably (i) filled with the pushed material and (ii) reduced by a polishing effect. These assumptions would corroborate the main friction components on the $A+R$ specimen surface being the sum of $\mu_{\text {asperity }}$ and $\mu_{\text {debris. }}$ In any event, the friction components produced a lower friction than that found on specimen $A$, owing to coating adhesion.

Plots of penetration depth versus load along the scratch are shown in Figure 7. The penetration curves were automatically calculated by subtracting the original morphology from the scratch and residual profile data using the nanoindenter Testworks $^{(R)}$ software. The penetration curves exhibited a resultant track depth of 3 $\mu \mathrm{m}$ and $4 \mu \mathrm{m}$ at maximum scratch load for the $A$ and $A+R$ specimens, respectively. These results indicate that the damage observed on the $A+R$ specimen was greater than that on the $A$ specimen. The generation of wear debris particles, visible as bright spots at higher magnifications in Figure 8, probably produced the arising damage as a result of a polishing mechanism of the surface asperity.

Archanta et al. [42, 43] reported that, in this type of tribosystem, wear particles continued to form during the subsequent sliding test cycles, some of those particles agglomerating and being pulled out from the wear track as large wear particles. In the present study, the rutile grains were expected to act as abrasive material or as a tribo- 
layer, but no evidence was found in this regard. Several cyclical scratch experiments at constant load would reveal the wear mechanism that occurred under these test conditions and further research is needed on this issue.

The above findings show that the damage resistance and friction behaviour of the studied $\mathrm{TiO}_{2}$ layers depended on how the microstructures were distributed in the coating surface. Although the resultant hardness of the $A+R$ coating was higher than that of the $A$ specimen surface, the tribological properties displayed different behaviour owing to the nature of the slide and wear mechanism. In photocatalytic applications, high anatase content is essential to reach the required photocatalytic activity. This scenario needs to be taken into account when photoactive surfaces are deposited, independently of the technique involved, because a comprise needs to be found between the mechanical and the photocatalytic properties by controlling the microstructure and phases contained in the layers.

\section{Conclusions}

In this study, suspension plasma sprayed $\mathrm{TiO}_{2}$ coatings, which were cooled either in air or with water, exhibited a homogeneous anatase and rutile phase distribution or recrystallised anatase on surface, respectively. Under the plasma spray test conditions used, all the feedstock melted, temperatures being reached above that at which the material undergoes rutile transformation. However, depending on the cooling rate, the melted material was also able to re-crystallise into anatase, this being the case with the coating obtained on the water-cooled substrate.

The nanoindentation technique proved to be a useful method of characterising the arising phases, which consisted of anatase nano-crystals and rutile micro particles that displayed a hardness of $8.5 \mathrm{GPa}$ and $16.5 \mathrm{GPa}$, respectively. The nanoscratch experiments confirmed that coatings with uniformly distributed rutile exhibited lower scratch resistance than the coatings with re-crystallised anatase, owing to the abrasive behaviour of the harder rutile phase. The higher friction coefficient obtained on the anatase surface $(\mu=0.7)$ compared with that obtained on the anatase + rutile surface 
$(\mu=0.3)$ also needs to be taken into account. The spherical indenter used in the scratch tests could be suitably used in further wear research because the linearity of the friction behaviour assures detection of any cohesive or adhesive failure.

\section{Acknowledgements}

The study was financially supported by the Spanish Ministry of Science and Innovation (PID-600200-2009-5 and MAT2009-14144-C03-01 -02).

\section{References}

[1] Rajab, F.M., Loaring, D., Ziegler, K.J 'Preparing thick, defect-free films of anatase titania for dye-sensitized solar cells' Thin Solid Films, 519 (19) (2011) 6598-6604

[2] Roméas V., Pichat P., Guillard C., Chopin T., Lehaut C. 'Testing the efficacy and the potential effect on indoor air quality of a transparent self-cleaning $\mathrm{TiO}_{2}$-coated glass through the degradation of a fluoranthene layer' Industrial and Engineering Chemistry Research 38 (10) (1999) 3878-3885

[3] K.S. Yao, T.C. Cheng, S.J. Li, L.Y. Yang, K.C. Tzeng, C.Y. Chang, Y. Ko 'Comparison of photocatalytic activities of various dye-modified $\mathrm{TiO}_{2}$ thin films under visible light' Surf. Coat. Technol. 203, 5-7 (2008) 922-924

[4] L. Lopez, W.A. Daoud, D. Dutta, 'Preparation of large scale photocatalytic $\mathrm{TiO}_{2}$ films by the sol-gel process', Surf. Coat. Technol. 205, 2 (2010) 251-257

[5] MD.K. Nazeeruddin, M. Grätzel, 'Conversion and storage of solar energy using dyesensitized nanocrystalline $\mathrm{TiO}_{2}$ Cells' Comprehensive Coordination Chemistry II, 9, (2003) 719758

[6] Hua Tiana, Junfeng Ma, Kang Li, Jinjun Li ‘Photocatalytic degradation of methyl orange withW-doped $\mathrm{TiO}_{2}$ synthesized by a hydrothermal method' Mater. Chem. Phys 112 (2008) 4751.

[7] Romana Khan, SunWoo Kim, Tae-Jeong Kim, Chang-Mo Nam, 'Comparative study of the photocatalytic performance of boron-iron Co-doped and boron-doped TiO2 nanoparticles' Mater. Chem. Phys. 112 (2008) 167-172. 
[8] Lihong Zhang, Peijun Li, Zongqiang Gong, Xuemei Li, 'Photocatalytic degradation of polycyclic aromatic hydrocarbons on soil surfaces using $\mathrm{TiO}_{2}$ under UV light' J. Hazard. Mater 158 (2008) 478-484.

[9] A. Chabas, T. Lombardo, H. Cachier, M.H. Pertuisot, K. Oikonomou, R. Falcone, M. Verita, F. Geotti-Bianchini, 'Behaviour of self-cleaning glass in urban atmosphere' Building and Environment 43 (2008) 2124-2131.

[10] Akira Fujishima, Xintong Zhang, Titanium dioxide photocatalysis: present situation and future approaches', C. R. Chim. 9 (2006) 750-760.

[11] C. Euvananont, C. Junin, K. Inpor, P. Limthongkul, C. Thanachayanont ' $\mathrm{TiO}_{2}$ optical coating layers for self-cleaning applications' Ceramics International 34 (2008) 1067-1071.

[12] Foster H.A., Ditta I.B., Varghese S., Steele A. 'Photocatalytic disinfection using titanium dioxide: Spectrum and mechanism of antimicrobial activity', Applied Microbiology and Biotechnology, 90, 6 ( 2011) 1847-1868.

[13] Mehrabadi, A.R. , Kardani N. , Fazeli M. , Hamidian L. , Mousavi A. , Salmani N. 'Investigation of water disinfection efficiency using titanium dioxide $\left(\mathrm{TiO}_{2}\right)$ in permeable to sunlight tubes', Desalination and Water Treatment, 28, 1-3, (2011) 17-22.

[14] Koichi Nakaso, Kikuo Okuyama, Manabu Shimada, Sotiris E. Pratsinis 'Effect of reaction temperature on CVD-made $\mathrm{TiO}_{2}$ primary particle diameter' Chem. Eng. Sci. 58 (2003) 33273335.

[15] Yijun Sun , Aizhen Li, Ming Qi, Liangying Zhang, Xi Yao 'High surface area anatase titania nanoparticles prepared by MOCVD' Mater. Sci. Eng., B 86 (2001) 185-188.

[16] A.P. Caricato, M.G. Manera, M. Martino, R. Rella, F. Romano, J. Spadavecchia, T. Tunno, D. Valerini 'Uniform thin films of $\mathrm{TiO}_{2}$ nanoparticles deposited by matrix-assisted pulsed laser evaporation' Appl. Surf. Sci. 253 (2007) 6471-6475.

[17] D. Glföß, P. FrachT, O. Zywitzki, T. Modes, S. Klinkenberg, C. Gottfried 'Photocatalytic titanium dioxide thin films prepared by reactive pulse magnetron sputtering at low temperature' Surf. Coat. Technol. 200 (2005) 967-971.

[18] Vicent M., Sánchez E., Santacruz I., Moreno R. Nanostructured granules by spray-drying , J. Eur. Ceram. Soc. 31 (8), (2011) 1413-1419. 
[19] Zeng Yi, Juntao Li, Wu Wei, Jianrong Wang, Soo Wohn Lee, Ceram. Int. 34 (2008) 351-357

[20] G. Bolelli, V. Cannillo, R. Gadow, A. Killinger, L. Lusvarghi, J. Rauch, Surf. Coat. Technol. 203 (2009) 1722-1732.

[21] F.L. Toma, L.M. Berger, C.C. Stahr, T. Naumann, S. Langner, J. Therm. Spray Technol. 19 (2010) 262-274.

[22] Kozerski S., Toma F.-L., Pawlowski L., Leupolt B., Latka L., Berger L.-M., Suspension plasma sprayed $\mathrm{TiO}_{2}$ coatings using different injectors and their photocatalytic properties' Surf. Coat. Technol. 205 (4) (2010) 980-986.

[23] Baoshun Liua, LipingWen, Xiujian Zhao 'The study of photocatalysis under ultraviolet + visible two-beam light irradiation using undoped nano-titanium dioxide', Mater. Chem. Phys. 112 (2008) 35-40.

[24] Golberg-Oster O., Bar-Ziv R., Yardeni G., Zilbermann I., Meyerstein D. 'On the reactions of methyl radicals with $\mathrm{TiO}_{2}$ nanoparticles and granular powders immersed in aqueous solutions', Chem. Eur. J., 17 (33), (2011) 9226-9231.

[25] Khameneh Asl S., Kianpour Rad M., Sadrnezhaad S.K., Vaezi M.R, 'The effect of microstructure on the photocatalytic properties of $\mathrm{TiO}_{2}{ }^{\prime}$ Adv. Mater. Res. 264-265 (2011) 13401345.

[26] Z. Ding, G.Q. Lu, P.F. Greenfield, 'Role of the Crystallite Phase of TiO2 inHeterogeneous Photocatalysis for Phenol Oxidation in Water' J. Phys. Chem. B (2000) 104, 4815-4820

[27] Roman Jaworski, Lech Pawlowski, Francine Roudet, Stefan Kozerski, Fabrice Petit 'Characterization of mechanical properties of suspension plasma sprayed TiO2 coatings using scratch test' Surf. Coat. Tech. 202 (2008) 2644-2653

[28] Bannier E., Darut G., Sánchez E., Denoirjean A., Bordes M.C., Salvador M.D., Rayón E., Ageorges H. 'Microstructure and photocatalytic activity of suspension plasma sprayed $\mathrm{TiO}_{2}$ coatings on steel and glass substrates' Surf. Coat. Tech. 206, 2-3 (2011) 378-386

[29] Oliver WC. and Phar G.M 'An improved technique for determining hardness and elastic modulus using load and displacement sensing indentation experiments' J. Mater. Res. 7 (6) (1992) $1567-1580$ 
[30] V. Bonache, E. Rayón, M.D. Salvador, D. Busquets 'Nanoindentation study of WC-12Co hardmetals obtained from nanocrystalline powders: Evaluation of hardness and modulus on individual phases' Mater. Sci. Eng. A 527 (2010) 2935-2941

[31] J.J. Roa, E. Jiménez-Piqué, T. Puig, X. Obradors, M. Segarra,' Nanoindentation of multilayered epitaxial $\mathrm{YBa}_{2} \mathrm{Cu}_{3} \mathrm{O}_{7}-\delta$ thin films and coated conductors 'Thin Solid Films 519,8 (2011) $2470-2476$

[32] Y. Hu, H.-L. Tsai, C.-L. Huang, 'Phase transformation of precipitated $\mathrm{TiO}_{2}$ nanoparticles'.Mater. Sci. Eng., A 344 (2003) 209-214.

[33] Filofteia-Laura Toma, Ghislaine Bertrand, Sylvie Begin, Cathy Meunier, Odile Barres, Didier Klein, Christian Coddet, 'Microstructure and environmental functionalities of $\mathrm{TiO}_{2}$-supported photocatalysts obtained by suspension plasma spraying ', Appl. Catal., B 68, 1-2, 26 (2006) 7484

[34] V. Canseco, J.J. Roa, E. Rayón, A.I. Fernández, E. Palomo,' Mechanical characterization at nanometric scale for heterogeneous graphite-salt phase change materials with a statistical approach '. Ceram. Int., (2011) doi:10.1016/j.ceramint.2011.07.021

[35] E. Rayón, V. Bonache, M.D. Salvador, J.J. Roa, E. Sánchez, 'Hardness and Young's modulus distributions in atmospheric plasma sprayed WC-Co coatings using nanoindentation 'Surf. Coat. Tech. 205, 17-18, (2011) 4192-4197.

[36] Handbook of Ceramics, Charles A. Harper, McGraw-Hill, 2001

[37] R. Saha, W.D. Nix, Acta Mater. 50 (2002) 23

[38] B. Bhushan, M. Nosonovsky. Comprehensive model for scale effects in friction due to adhesion and two- and three-body deformation', Acta Mater. 52 (2004) 2461.

[39] B. Bhushan, M. Nosonovsky, 'Scale effects in friction using strain gradient plasticity and dislocation-assisted sliding', Acta Mater. 51 (2003) 4331

[40] J. Zhang, F.A. Moslehy, S.L. Rice, 'A model for friction in quasi-steady-state Part I. Derivation' Wear, 149 (1991) 1-12

[41] J. Zhang, F.A. Moslehy, S.L. Rice, A model for friction in quasi-steady-state sliding Part II. Numerical results and discussion', wear, 149 (1991) 13-25. 
[42] S. Achanta, D. Drees, J.-P. Celis, 'Friction and nanowear of hard coatings in reciprocating sliding at milli-Newton loads', Wear, 259, 1-6 (2005) 719-729

[43] S. Achanta, T. Liskiewicz, D. Drees, J.-P. Celis, 'Friction mechanisms at the micro-scale', Tribology International, 42, 11-12 (2009) 1792-1799 